Caring : Jurnal Keperawatan

Vol.8, No. 1, Maret 2019, pp. $23-31$

ISSN 1978-5755 (Online)

DOI: 10.29238

Journal homepage: http://e-journal.poltekkesjogja.ac.id/index.php/caring/

\title{
Pengaruh kompres hangat terhadap nyeri leher pada penderita hipertensi esensial di wilayah Puskesmas Depok I, Sleman Yogyakarta
}

\section{The effect of warm compresses on neck pain in patients with essential hypertension in the area of Puskesmas Depok I, Sleman Yogyakarta}

\author{
Siti Fadlilah ${ }^{1 a^{*}}$ \\ ${ }^{1}$ Program Pendidikan Profesi Ners Universitas Respati Yogyakarta \\ a sitifadlilah@respati.ac.id
}

\section{ARTICLE INFO}

\section{Article history}

\section{Keywords:}

Hypertension

Pain

Warm compress

\section{A B S T R A C T / A B S T R A K}

Hypertension is increasing blood pressure in the artery. Signs and indication arise from this disease are a dizzy, headache, painful in the nape of the neck (neck pain), easily angered, and hard to breathe. This neck pain can offend essential hypertension in daily patient activities. One of the non pharmacological actions to decrease or overcome the neck pain is by a warm compress. The warm compress is giving a sense of warm/heat in a certain area. This research is purposed to find out the influence of warm compress towards neck pain in essential hypertension patients. This research is carried out in Puskesmas Depok I area, Sleman, Yogyakarta. Type of this research is quasi-experiment with pre-test posttest with control group design. Several samples consist of 40 respondents and divided into two groups, which are 20 respondents of the intervention group and 20 respondents of the control group. Statistic test used in this research is Wilcoxon and Mann Whitney tests. Before applying pre-test, 12 respondents (60\%) are having moderate pain, and after giving warm compress (post-test), 17 respondents (75\%) are having minor pain. There is a significant scale of neck pain before and after the warm compress treatment ( $p$-value = 0,003 ) as well as contrast scale of neck pain between intervention group and control group ( $p$-value $=0,000)$. There is the influence of warm compress towards neck pain in essential hypertension patients in Puskesmas Depok I area, Sleman, Yogyakarta.

Hipertensi adalah peningkatan tekanan darah dalam arteri. Tanda dan gejala yang muncul dari penyakit hipertensi ini adalah pusing, sakit kepala, tengkuk terasa pegal (nyeri leher), mudah marah, sulit bernafas. Tengkuk terasa pegal atau nyeri leher dapat menggangu aktivitas sehari-hari penderita hipertensi esensial. Salah satu tindakan non farmakologis untuk mengurangi atau mengatasi nyeri leher yaitu kompres hangat. Kompres hangat adalah pemberian rasa hangat/panas didaerah tertentu. Penelitian bertujuan untuk mengetahui pengaruh kompres hangat terhadap nyeri leher pada penderita hipertensi esensial. Penelitian ini dilakukan di Wilayah Puskesmas Depok I, Sleman, Yogyakarta. Jenis penelitian ini adalah quasi eksperimen dengan desain pre test post test with control group. Dengan besar sampel sebayak 40 responden yang terbagi dalam 2 kelompok yaitu 20 responden kelompok intervensi dan 20 responden kelompok kontrol. Uji statistik yang digunakan dalam penelitian ini yaitu uji wilcoxon 
dan Mann Whitney. Sebagian besar responden sebelum perlakukan (pre test) mengalami nyeri sedang sebanyak 12 responden $(60 \%)$ dan setelah diberikan kompres hangat (posttest) sebagian besar responden mengalami nyeri ringan yaitu sebanyak 17 responden (75\%). Terdapat pengaruh yang signifikan skala nyeri leher sebelum dan sesudah diberikan kompres hangat $(P$ value $=0,003)$. Terdapat perbedaan yang signifikan skala nyeri kelompok intervensi dan kelompok kontrol $(P$ value $=0,000)$. Kompres hangat dapat menurunkan skala nyeri leher pada penderita hipertensi esensial.

Copyright (C) 2019 Caring : Jurnal Keperawatan. All rights reserved

\section{${ }^{\star}$ Corresponding Author:}

Siti Fadlilah,

Program Pendidikan Profesi Ners Universitas Respati Yogyakarta,

Jln. Laksda Adi Sucipto, Ambarukmo, Caturtunggal, Sleman, D I Yogyakarta

\section{PENDAHULUAN}

Hipertensi adalah peningkatan tekanan darah di dalam arteri. Darah akan memberikan gaya yang lebih tinggi dibandingkan kondisi normal secara persisten pada sistem sirkulasi. Pada umumnya, tekanan yang dianggap optimal adalah $120 \mathrm{mmHg}$ untuk tekanan sistoliknya dan $80 \mathrm{mmHg}$ untuk tekanan diastoliknya, sementara tekanan yang dianggap hipertensi adalah lebih dari $140 \mathrm{mmHg}$ untuk sistolik, dan lebih dari 90 $\mathrm{mmHg}$ untuk diastolik (Suzane\&Smeltzer, 2010).

Penderita hipertensi sudah mencapai seperempat jumlah populasi penduduk dunia. Data World Health Organization (WHO) dan The International Society of Hipertension (ISH) memuat saat ini terdapat 600 juta penderita hipertensi di seluruh dunia. Pada bulan September 2011 hipertensi menyebabkan kematian 1,5 juta kematian di Wilayah Asia Tenggara (Kartikasari, 2012). Di dalam penelitian Ruhyana (2007) menyebutkan angka kejadian tekanan darah tinggi atau hipertensi di dunia hampir 1 milyar orang atau 1 dari 4 orang dewasa menderita tekanan darah tinggi atau hipertensi. Selain itu menurut penelitian Suidah (2011) kurang lebih 10-30\% penduduk hampir semua negara mangalami hipertensi. Data Riskesdes tahun 2013 menyebutkan prevalensi hipertensi di Indonesia mencapai $25,8 \%$ dengan insiden komplikasi penyakit kardiovaskuler lebih banyak pada perempuan $52 \%$ dan pada laki-laki $48 \%$. Berdasarkan data Departemen Kesehatan Indonesia prevalensi hipertensi di Indonesia mencapai $31,7 \%$ dari populasi pada usia 18 tahun ke atas. Di Yogyakarta masuk dalam 5 besar kejadian hipertensi, pada tahun 2012 di daerah pedesaan presentasenya $51,7 \%$ dan di kota besar presentasenya 47,7\% (Riskesdas, 2013).

Kelainan pada tekanan darah lainnya yaitu hipotensi. Menurut penelitian Indra, Widodo, \& Widyastuti (2016) menyebutkan angka kejadian hipotensi ortostatik di Amerika Serikat $30 \%$ orang dewasa yang lebih tua dan sampai $70 \%$ dari penghuni panti jompo. Lebih lanjut, berdasarkan penelitian yang dilakukan Keller (2013) di dalam penelitian Indra, Widodo, \& Widyastuti (2016), didapatkan hasil bahwa kejadian hipotensi ortostatik terjadi pada 47-58 \% pasien dengan penyakit Parkinson, 13-32 \% dari mereka dengan hipertensi, 16-25\% dari mereka dengan diabetes mellitus dan 24 $\%$ dari mereka dengan stenosis arteri karotis. Sedangkan hipotensi ortostatik di Indonesia 12,65\% yang disebutkan Siti (2004) dalam penelitian Sriminanda et al (2014) di bebagai praktek dokter di kabupaten Indonesia.

Hipertensi berdasarkan penyebabnya dibagi menjadi 2 yaitu hipertensi sekunder dan hipertesi primer. Hipertensi sekunder adalah hipertensi yang disebabkan oleh penyakit sedangkan hipertensi primer atau nama lainya hipertensi esensial yaitu hipertensi yang tidak diketahui penyebabnya (Suzane\&Smeltzer, 2010).. Adapun faktorfaktor yang mempengarahu hipertensi seperti keturunan, jenis kelamin, umur, kegemukan, konsumsi garam berlebihan, kurang olahraga, konsumsi alkohol dan 
merokok dan stres (Dalimartha, 2008). Adapun tanda dan gejala yang menyertai hipertensi seperti: jantung berdebar-debar, sulit bernafas setelah bekerja keras, mudah lelah, mudah marah, tengkuk terasa tegang/nyeri leher, sukar tidur, dan sebagainya (Vitahealth, 2001).

Tengkuk terasa tegang atau nyeri leher diakibatkan karena terjadi peningkatan tekanan pada dinding pembuluh darah di daerah leher yang mana pembuluh darah tersebut membawa darah ke otak sehingga ketika terjadi peningkatan tekanan vaskuler ke otak yang mengakibatkan terjadi penekanan pada serabut saraf otot leher sehingga penderita merasa nyeri atau ketidaknyamanan pada leher. Nyeri yang dirasakan oleh penderita hipertensi akan menggangu aktivitasnya sehari-hari. Salah satu terapi nonfarmakologis yang digunakan untuk meredakan nyeri salah satunya kompres hangat.

Berdasarkan hasil studi pendahuluan yang telah dilakukan oleh peneliti pada Wilayah Puskesmas Depok I, Sleman, Yogyakarta didapatkan jumlah penderita hipertensi primer berjumlah sekitar 613 orang. Laki-laki berjumlah 180 orang sedangkan wanita berjumlah 430 orang. Dari hasil wawancara dengan 7 responden yang menderita hipertensi, 5 mengatakan sering mengalami nyeri leher. Mereka menggunakan balsem atau digosok dengan minyak untuk mengatasi nyeri leher tersebut, 2 orang mengatakan membiarkan saja bila mengalami nyeri leher. Berdasarkan fakta yang telah diuraikan maka peneliti tertarik untuk melakukan penelitian untuk mengurangi atau menghilangkan nyeri dengan cara non farmakologi yaitu kompres hangat pada penderita hipertensi esensial.

\section{BAHAN DAN METODOLOGI PENELITIAN}

Jenis penelitian yang dilakukan dengan menggunakan metode penelitian quasi eksperimen. Desain penelitian pre test-post test with control group. Populasi dalam penelitian ini adalah seluruh penderita hipertensi di Wilayah Kerja Puskesmas Depok 1, Maguwoharjo, Sleman, Yogyakarta tahun 2016 berjumlah 613 orang. Sampel penelitian adalah penderita hipertensi esensial di Wilayah Puskesmas Depok I, Sleman, Yogyakarta yang memenuhi kriteria inklusi dan berjumlah 40 responden dengan teknik Accidental Sampling. Pada penelitian ini terdiri dari 2 kelompok yaitu kelompok intervensi terdiri dari 20 responden dan diberikan perlakuan kompres hangat dan kelompok control terdiri dari 20 responden dan tidak diberikan perlakuan. Variabel bebasnya kompres hangat dan variabel terikatnya nyeri leher penderita hipertensi esensial. Analisa data digunakan untuk mendeskripsikan karateristik responden yaitu usia, jenis kelamin, pekerjaan, nyeri pre test-post test pada kelompok intervensi dan kelompok kontrol. Uji statistik yang di gunakan adalah uji Wilcoxon dan uji Mann Whitney.

\section{HASIL DAN PEMBAHASAN}

Karateristik Responden

Distribusi frekuensi responden di Wilayah Puskesmas Depok I, Sleman, Yogyakarta berdasarkan usia dan jenis kelamin disajikan pada Tabel 1 sebagai berikut

Tabel 1. Distribusi Frekuensi Berdasarkan Karateristik Responden Pada Pengaruh Kompres Hangat Terhadap Nyeri Leher Pada Penderita Hipertensi Esensial

\begin{tabular}{ccccc}
\hline $\begin{array}{c}\text { Karakteristik } \\
\text { responden }\end{array}$ & \multicolumn{2}{c}{ Kelompok kontrol } & \multicolumn{2}{c}{ Kelompok intervensi } \\
\cline { 2 - 5 } & $\begin{array}{c}\text { Frekuensi } \\
(\mathbf{f})\end{array}$ & $\begin{array}{c}\text { Persentase } \\
(\%)\end{array}$ & $\begin{array}{c}\text { Frekuensi } \\
(\mathbf{f})\end{array}$ & $\begin{array}{c}\text { Persentase } \\
(\%)\end{array}$ \\
\hline Usia & & & & \\
$31-39$ & 0 & 0 & 5 & 25,0 \\
$40-49$ & 5 & 25,0 & 8 & 40,0 \\
$>50$ & 15 & 75,0 & 7 & 35,0 \\
\hline
\end{tabular}




\begin{tabular}{ccccc}
\hline $\begin{array}{c}\text { Jenis kelamin } \\
\text { Laki-laki }\end{array}$ & 3 & 15,0 & 2 & 10,0 \\
Prempuan & 17 & 85,0 & 18 & 90,0 \\
\hline Pekerjaan & 12 & 60,0 & 11 & 55,0 \\
IRT & 2 & 10,0 & 5 & 25,0 \\
Petani & 4 & 20,0 & 4 & 20,0 \\
Wiraswasta & 1 & 5,0 & 0 & 0,0 \\
Buruh & 1 & 5,0 & 0 & 0,0 \\
PNS & 20 & 100 & 20 & 100 \\
\hline Total & 2018 &
\end{tabular}

Sumber: Data Primer 2018

Tabel 1 diketahui bahwa responden pada kelompok kontrol sebagaian besar berumur $>50$ tahun yaitu sebanyak 15 responden $(75 \%)$. Mayoritas responden dalam kelompok kontrol berjenis kelamin perempuan sebanyak 17 responden (85\%). Pada kelompok intervensi mayoritas responden berusia 41-49 tahun sebanyak 8 responden $(40 \%)$ dan berjenis kelamin perempuan yaitu sebanyak 18 responden $(90 \%)$.

Distribusi frekuensi responden di Wilayah Puskesmas Depok I, Sleman, Yogakarta berdasarkan skala nyeri kelompok intervensi disajikan pada tabel 2.

Tabel 2. Distribusi Frekuensi Skala Nyeri Pre test- Post test Kelompok Intervensi Pada

\begin{tabular}{ccccc} 
& \multicolumn{3}{c}{ Pengaruh Kompres Hangat Terhadap Nyeri } \\
\hline \multirow{2}{*}{ Skala nyeri } & \multicolumn{3}{c}{ Pretest } & \multicolumn{2}{c}{ Post test } \\
\cline { 2 - 5 } & Frekuensi (f) & Persentase (\%) & Frekuensi (f) & Persentase (\%) \\
\hline Ringan & 8 & 40,0 & 17 & 85,0 \\
Sedang & 12 & 60,0 & 3 & 15,0 \\
\hline Total & 20 & 100 & 20 & 100 \\
\hline
\end{tabular}

Sumber: Data Primer 2018

Tabel 2 diketahui bahwa skala nyeri sebelum dilakukan kompres hangat (pre test), mayoritas responden mengalami nyeri sedang yaitu sebanyak 12 responden $(60 \%)$. Dan skala nyeri setelah dilakukan kompres hangat (post test), mayoritas responden mengalami nyeri ringan yaitu sebanyak 17 responden (85\%).

Distribusi frekuensi responden di Wilayah Puskesmas Depok I, Sleman, Yogakarta berdasarkan skala nyeri kelompok kontrol disajikan pada tabel 3.

Tabel 3. Distribusi Frekuensi Skala Nyeri Pre test-Post test Kelompok Kontrol Pada Pengaruh Kompres Hangat Terhadap Nyeri Leher

\begin{tabular}{ccccc}
\hline \multirow{2}{*}{ Skala nyeri } & \multicolumn{2}{c}{ Pretest } & \multicolumn{2}{c}{ Post test } \\
\cline { 2 - 5 } & Frekuensi (f) & Persentase (\%) & Frekuensi (f) & Persentase (\%) \\
\hline Ringan & 5 & 25,0 & 5 & 25,0 \\
Sedang & 15 & 75,0 & 15 & 75,0 \\
\hline Total & 20 & 100 & 20 & 100 \\
\hline
\end{tabular}

Sumber: Data Primer 2018

Tabel 3 diketahui bahwa skala nyeri sebelum dilakukan pre test mayoritas responden mengalami nyeri sedang yaitu sebanyak 15 responden (75\%). Dan setelah dilakukan post test mayoritas responden mengalami nyeri sedang yaitu sebanyak 15 responden (75\%).

Distribusi nyeri leher pre test dan post test pada penderita hipertensi esensial setelah diberikan kompres hangat pada kelompok intervensi disajikan pada tabel 4. 
Tabel 4. Tabulasi Silang Pengaruh Kompres Hangat Terhadap Nyeri Leher Penderita Hiperetensi Esensial Pada Kelompok Intervensi

\begin{tabular}{cccccccc}
\hline & \multicolumn{7}{c}{ Skala nyeri posttest } \\
\hline \multirow{2}{*}{$\begin{array}{c}\text { Skala nyeri } \\
\text { pretest }\end{array}$} & \multicolumn{9}{c}{ Ringan } & \multicolumn{2}{c}{ Sedang } & \multicolumn{2}{c}{ Total } & \multirow{2}{*}{ p-value } \\
\cline { 2 - 7 } & $\mathbf{f}$ & $\%$ & $\mathbf{f}$ & $\%$ & $\mathbf{f}$ & $\%$ & \\
\hline Ringan & 8 & 40 & 0 & 0 & 8 & 40 & \\
Sedang & 9 & 45 & 3 & 15 & 12 & 60 & \multirow{2}{*}{0,003} \\
\hline Total & 17 & 85 & 3 & 15 & 20 & 100 & \\
\hline Sumber: Data Primer 2018 & & & & &
\end{tabular}

Tabel 4 diketahui bahwa saat pre test pada kelompok intervensi sebanyak 8 responden $(40 \%)$ mengalami nyeri ringan dan saat post test tetap mengalami ringan. Pada saat pre test sebanyak 12 responden (60\%) mengalami nyeri sedang dan saat post test mayoritas responden mengalami nyeri ringan yaitu 9 responden (45\%). Hasil uji statistik dengan menggunakan uji wilcoxon menunjukan bahwa nilai $P$ value $=0,003$ dengan taraf signifikasi $5 \%(0,05)$, dapat ditarik kesimpulan bahwa Ha diterima dimana nilai $P$ value $=0,003<0,05$ hal ini menunjukan bahwa ada pengaruh pemberian kompres hangat terhadap nyeri leher pada penderita hipertensi esensial di Wilayah Puskesmas Depok I, Sleman, Yogyakarta.

Distribusi nyeri leher pre test dan post test pada penderita hipertensi esensial pada kelompok kontrol disajikan pada tabel 5.

Tabel 5. Tabulasi Silang Pengaruh Kompres Hangat Terhadap Nyeri Leher Penderita Hipertensi Esensial Pada Kelompok Kontrol

\begin{tabular}{cccccccc}
\hline & \multicolumn{7}{c}{ Skala nyeri posttest } \\
\hline \multirow{2}{*}{$\begin{array}{c}\text { Skala nyeri } \\
\text { pretest }\end{array}$} & \multicolumn{2}{c}{ Ringan } & \multicolumn{2}{c}{ Sedang } & \multicolumn{2}{c}{ Total } & \multirow{2}{*}{ p-value } \\
\cline { 2 - 7 } & $\mathbf{f}$ & $\%$ & $\mathbf{f}$ & $\%$ & $\mathbf{f}$ & $\%$ & \\
\hline Ringan & 5 & 25 & 0 & 0 & 5 & 25 & \multirow{2}{*}{1,000} \\
Sedang & 0 & 0 & 15 & 75 & 15 & 75 & \\
\hline Total & 5 & 25 & 15 & 75 & 20 & 100 & \\
\hline Sumber: Data Primer 2018 & & & & &
\end{tabular}

Tabel 5 diketahui bahwa sebanyak 5 responden (25\%) saat pre test pada kelompok kontrol mengalami nyeri ringan dan saat post test tetap mengalami nyeri ringan. Sebanyak 15 responden (75\%) saat pre test mengalami nyeri sedang dan saat post test tetap mengalami nyeri sedang. Hasil uji statistik dengan menggunakan uji Wilcoxon menunjukan nilai $P$ value $=1,000$ dengan taraf signifikasi $5 \%(0,05)$ sehingga dapat ditarik kesimpulan $\mathrm{H} 0$ diterima dimana nilai $\mathrm{P}$ value $=1,000>0,05$ ini menunjukan bahwa tidak ada pengaruh skala nyeri pre test dan skala nyeri post test yang tidak diberikan perlakuan pada kelompok kontrol.

Perbedaan nyeri leher post test pada kelompok intervensi dan post test pada kelompok kontrol pada penderita hipertensi esensial disajikan pada tabel 6 .

Tabel 6. Perbedaan Skala Nyeri Post test Kelompok Intervensi dan Skala Nyeri Post test Kelompok Kontrol

\begin{tabular}{|c|c|c|c|}
\hline $\begin{array}{c}\text { Skala nyeri post } \\
\text { test }\end{array}$ & $f$ & Mean Rank & p-value \\
\hline Intervensi & 20 & 14,50 & 0,000 \\
\hline Kontrol & 20 & 26,50 & \\
\hline
\end{tabular}


Tabel 6 diketahui bahwa Mean Rank kelompok intervensi 14,50 sedangkan kelompok kontrol 26,50. Hasil uji statistik dengan menggunakan uji Mann Whitney menunjukan bahwa nilai $P$ value $=0,000$ yang artinya ada perbedaan yang signifikan antara skala nyeri kelompok intervensi dan skala nyeri kelompok kontrol.

Mayoritas responden pada kelompok intervensi mengalami nyeri sedang ketika dilakukan pre test sebelum diberikan kompres hangat yaitu sebanyak 12 reponden $(60 \%)$. Hal ini berarti mayoritas penderita hipertensi esensial di Wilayah Puskesmas Depok I mengalami nyeri sedang dengan skala nyeri 4-6. Hal ini mendukung penelitian yang dilakukan oleh Marlingga (2011), tentang pengaruh stimulasi kutaneus kompres panas basah terhadap penurunan nyeri sendi pada lansia dimana diperoleh skala nyeri pre test mayoritas responden mengalami nyeri sedang yaitu 16 responden (53,3\%). Namun ada beberapa penelitian yang berbeda yaitu penelitian yang dilakukan oleh Widyastuti (2012), tentang pengaruh kompres hangat terhadap nyeri sendi diperoleh skala nyeri pre test mayoritas responden mengalami nyeri berat sebanyak 20 responden $(74,1 \%)$. Penelitian lain yang dilakukan oleh Fanada (2012), tentang pengaruh kompres hangat dalam menurunkan nyeri rematik pada lansia diperoleh skala nyeri pre test, mayoritas responden mengalami nyeri dengan skala 3 . Menurut peneliti hal ini dikarenakan nyeri merupakan sesuatu yang bersifat subyektif dimana individu atau responden itu sendiri yang menjelaskan dan mengevaluasi perasaan yang dirassakan. Nyeri merupakan sensasi yang rumit, unik, universal, dan bersifat individual. Dikatakan individual karena respon individu terhadap sensasinya beragam dan tidak bisa disamakan satu dengan yang lain (Marlingga, 2011).

Pada kelompok intervensi setelah diberikan kompres hangat mayoritas responden mengalami nyeri ringan yaitu 17 responden (85\%) ketika dilakukan post test. $\mathrm{Hal}$ ini berarti mayoritas penderita hipertensi esensial di Wilayah Puskesmas Depok I setelah dilakukan kompres hangat, responden mengalami nyeri ringan dengan skala 13. Hal ini mendukung penelitian yang dilakukan oleh Widyastuti (2012), diperoleh skala nyeri post test mayoritas responden mengalami nyeri ringan yaitu sebanyak 14 responden (51,9\%). Dan penelitian yang dilakukan Fanada (2012), skala nyeri post test, mayoritas responden mengalami nyeri dengan skala 1 . Ini menunjukan bahwa terjadi penurunan skala nyeri setelah diberikan kompres hangat.

Nyeri leher yang dirasakan oleh responden, merupakan salah satu tanda dan gejala dari hipertensi. Seorang penderita hipertensi esensial akan mengalami peningkatan tekanan darah, salah satunya peningkatan tekanan dinding pembuluh darah di daerah leher sehingga terjadi peningkatan tekanan vaskuler ke otak yang mengakibatkan terjadinya penekanan pada serabut saraf otot leher sehingga penderita merasakan nyeri. Menurut peneliti ada beberapa faktor yang mempengaruhi nyeri yang dirasakan oleh responden seperti usia, jenis kelamin, pekerjaan.

Pada penelitian ini mayoritas responden yang mengalami nyeri berusia 41-49 tahun yaitu sebanyak 8 responden (40\%). Usia merupakan variabel yang sangat penting yang mempengaruhi nyeri, khususnya pada anak dan lansia dimana terjadi perbedaan dalam beraksi terhadap nyeri. Anak-anak mengalami kesulitan dalam memahami nyeri dan beranggapan bahwa apa yang dilakukan oleh perawat dapat menimbulakan nyeri sedangkan pada lansia nyeri yang mereka rasakan sangat kompleks, karena mereka umumnya memiliki banyak penyakit dengan gejala yang sama dan pada bagian tubuh yang lain Widyastuti, 2012; Fanada, 2012) Usia 41-49 merupakan usia dewasa dimana pada umumnya orang dewasa menganggap nyeri sebagai suatu kelemahan, kegagalan dan kehilangan kontrol. Orang dewasa melaporkan nyeri ketika sudah patologis atau terjadi kerusakan fungsi (Asmadi, 2008).

Mayoritas responden dalam dalam kelompok intervensi berjenis kelamin perempuan yaitu 18 responden (90\%) dan bekerja sebagai ibu rumah tangga sebayak 11 responden (55\%). Perempuan mudah merasakan nyeri dibandingkan laki-laki hal ini didukung oleh beberapa kebudayaan yang mempengaruhi jenis kelamin misalnya 
mengangap seorang anak laki-laki harus berani dan tidak boleh menangis sedangkan anak perempuan boleh menangis dalam situasi yang sama. Perempuan memiliki tingkat ambang batas nyeri dan tingkat toleransi nyeri lebih rendah dibandingkan dengan lakilaki (Judha, 2012). Bekerja sebagai ibu rumah tangga dituntut harus mengerjakan semua urusan atau pekerjaan rumah tangga dengan jam kerja yang tidak terbatas seperti membersihkan rumah, memasak, mencuci, mengurus anak dan suami. Tugas ibu rumah tangga dalam kehidupan keluarga yaitu mengatur tatalaksana rumah tangga sehingga kondisi keluarga menjadi teratur dan rapih. Pekerjaan sebagai ibu rumah tangga dapat mempengaruhi nyeri yang dirasakan hal ini dikarenakan pekerjaan yang dilakukan merupakan pekerjaan fisik dengan jam kerja yang tidak terbatas sehingga ibu rumah tangga mudah untuk mengalami stres (Potter\&Perry, 2009). Ketika seseorang mengalami stres fungsi hipotalamusnya tergangu yang mengakibatkan saraf simpatis terangsang dampaknya adalah denyut jantung meningkat sehingga tekanan darah juga mengalami peningkatan. Seseorang yang memiliki riwayat hipertensi atau menderita hipertensi ketika mengalami stres akan berdampak pada tekanan darahnya yaitu tekanan darahnya menjadi tinggi dan dapat mengalami nyeri leher (Farida, 2010).

Salah satu tindakan nonfarmakologis untuk mengilangkan nyeri atau mengurangi nyeri adalah kompres hangat. Kompres hangat dapat memberikan rasa hangat pada daerah tertentu, karena panas yang dihasilkan mampu mendilatasi pembuluh darah sehingga aliran darah dan suplai oksigen akan lancar, sehingga meredakan ketegangan otot akibatnya nyeri dapat berkurang (Ociviyanti, 2013). Berdasarkan hasil uji statistik dengan menggunakan uji wilcoxon didapatkan hasil terjadi penurunan skala nyeri leher setelah diberikan kompres hangat dibuktikan dengan nilai $P$ value $=0,003$ yang berarti bahwa ada pengaruh yang signifikan pemberian kompres hangat terhadap nyeri leher pada penderita hipertensi esensial.

Hasil penelitian ini mendukung penelitian yang dilakukan oleh Widyastuti (2012), tentang pengaruh kompres hangat terhadap nyeri sendi diperoleh skala nyeri pre test mayoritas responden mengalami nyeri berat sebanyak 20 responden $(74,1 \%)$. Setelah diberikan kompres hangat (post test) sebagian besar responden mengalami nyeri ringan yaitu 14 responden (51,9\%). Peneliti lain tentang kompres hangat oleh Fanada (2012), dimana ketika dilakukan pre test diperoleh mayoritas responden mengalami nyeri dengan skala 3 dan post test sebagian besar responden mengalami nyeri dengan skala 1 .

Penelitian yang dilakukan Marlingga (2011), dimana ketika dilakukan pengukuran skala nyeri pre test diperoleh mayoritas responden mengalami nyeri sedang yaitu 16 responden $(53,3 \%)$ dan setelah diberikan stimulus kutaneus: kompres panas basah sebagian besar responden tidak merasakan nyeri yaitu 21 responden (70\%). Dari penelitian yang telah dilakukan oleh Widyastuti (2012), Fanada (2012) dan Marlingga (2011), diperoleh nilai nilai $P$ value 0,000 yang artinya ada pengaruh yang signifikan terhadap penurunan skala nyeri. Pada kelompok kontrol tidak ada pengaruh pemberian kompres hangat terhadap nyeri leher pada penderita hipertensi esensial hal ini dibuktikan dengan nilai $P$ value 1,000. Menurut peneliti hal ini dikarenakan pada kelompok kontrol tidak diberikan perlakuan atau intervensi sehingga tidak terjadi perubahan nyeri yang dialami responden. Hal ini juga terlihat ketika dilakukan pengukuran skala nyeri pre test dan post test mayoritas responden mengalami nyeri sedang yaitu 15 responden $(75 \%)$.

Pada kelompok kontrol mayoritas responden mengalami nyeri sedang yaitu 15 reponden (75\%) ketika dilakukan post test, dimana pada responden dalam kelompok ini tidak mengalami penurunan nyeri dikarenakan tidak diberikan intervensi atau perlakukan untuk mengurangi atau menurunkan nyeri yang dirasakan. Berdasarkan data penelitian responden dalam kelompok kontrol setelah dilakuka pre test dan post test terdapat 2 responden yang mengalami penurunan skala nyeri, namun karena peneliti langsung menginterpretasikan maka walaupun responden mengalami penurunan skala nyeri dari 
skala 6 menjadi 5 tetap peneliti menginterpretasikan nyeri sedang. Penurunan skala nyeri tersebut kemungkinan dipengaruhi oleh beberapa faktor yaitu kondisi rileks, dimana ketika kita dalam kondisi rileks ketegangan otot-otot kita berkurang.

Pada kelompok intervensi mayoritas responden ketika dilakukan post test mengalami nyeri ringan yaitu 17 responden (85\%). Responden dalam kelompok intervensi terjadi penurunan skala nyeri setelah diberikan kompres hangat dimana kompres hangat ini dapat mendilatasi pembuluh darah sehingga aliran darah akan lancar ke daerah yang mengalami nyeri. Berdasarkan data penelitian responden dalam kelompok intervensi setelah dilakukan pre test dan post test terdapat 3 responden yang tidak mengalami penurunan skala nyeri dimana 2 responden mengalami penurunan skala nyeri dari skala nyeri 6 menjadi 5 namun karena peneliti langsung menginterpretasikan skala nyeri sehingga walaupun ada penurunan skala tetap peneliti menginterpretasikan nyeri menjadi nyeri sedang. Sedangkan 1 responden dimana ketika dilakukan pre test dan post test responden ini tidak mengalami penurunan nyeri yaitu nyeri sedang dngan skala 4 .

Menurut peneliti kemungkinan ada beberapa hal yang dapat mempengaruhi intensitas nyeri yang dirasakan oleh responden pada kelompok intervensi yaitu usia, jenis kelamin, makna nyeri, perhatian, ansietas, dan keletihan. Beberapa faktor yang mempengaruhi nyeri yang dirasakan oleh responden yang meliputi: usia, jenis kelamin, kebudayaan, makna nyeri, perhatian, ansietas, keletihan, pengalaman sebelumnnya, gaya koping, dan dukungan keluarga (Widyastuti, 2012).

Skala nyeri post test pada kelompok intervensi dan skala nyeri post test pada kelompok kontrol berdasarakan hasil penelitian pada tabel 6 dimana Mean Rank kelompok intervensi 14,50 sedangkan kelompok kontrol 26,50. Hal ini menunjukan bahwa rata-rata nyeri yang dirasakan oleh responden setelah diberikan perlakuan berupa kompres hangat lebih kecil yaitu 14,50 dibandingkan rata-rata nyeri yang dirasakan oleh responden tanpa diberikan perlakuan atau intervensi yaitu 26,50 . Hal ini juga diperkuat dengan hasil uji statistik dengan menggunakan uji Mann Whitney didapatkan hasil nilai p value 0,000 yang berarti bahwa ada perbedaan skala nyeri leher post kelompok intervensi dan skala nyeri leher post kelompok kontrol.

\section{KESIMPULAN}

Hasil penelitian menunjukkan ada perbedaan signifikan antara skala nyeri kelompok kontrol dan intervensi. Hal ini dapat disimpulkan bahwa kompres hangat efektif menurunkan skala nyeri leher pada penderita hipertensi esensial di wilayah Puskesmas Depok I Sleman Yogyakarta. Berdasarkan hasil penelitian diharapkan penderita hipertensi dapat menerapkan teknik nofarmakologi untuk menjaga mengatasi nyeri leher yang diakibatkan oleh hipertensi.

\section{DAFTAR PUSTAKA}

Annies. 2006. Waspada penyakit Tidak Menular. Gramedia. Jakarta

Asmadi. 2008. Teknik Prosudural dan Aplikasi Kebutuhan Dasar Klien. Jakarta: Salemba medika. (online) books.google.com/books?isbn=9793027533 diaksestanggal 5 november 2016 pukul 19.00 wib.

Corwin, Elizabeth J. 2008. Buku Saku Patofisiologi. Jakarat: EGC

Dalimartha, S. 2008. Care Your Self Hipertensi. Jakarta: Gramedia

Fanada, M.2012. Pengaruh Kompres Hangat Dalam Menurunkan Skala Nyeri pada Lansia Yang Mengalami Nyeri Rematik Di Panti Sosial Tresna Werdha Teratai Palembang. Badan Diklat Propinsi Sumatra Selatan

Farida,

A. 2010

Chapter

II

pdf

http://repository.usu.ac.id/bitstream/123456789/20095/4/Chapter\%20ll.pdf 
Indra, B., Widodo, U., \& Widyastuti, Y. (2016). Perbandingan Insidensi Hipotensi Saat Induksi Intravena Propofol $2 \mathrm{Mg} / \mathrm{Kg}$ Bb Pada Posisi Supine dengan Perlakuan dan Tanpa Perlakuan Elevasi Tungkai. Jurnal Kesehatan Andalas, 5(1), 238-242.

Judha, M, dkk. 2012. Teori Pengukuran Nyeri \& Nyeri Persalinan. Yogyakarta: Nuha Medika.

Kartikasari , A N. 2012. Lam Murni BR Sagala. Perawatan Penderita Hipertensi di Rumah oleh Keluarga Suku Batak dan Suku Jawa di Kelurahan Lau Cimba Kabanjahe [internet]. c2011 [cited 2012 Feb 9]. p: 10-

Kemenkes RI., 2010. Profil Kesehatan Indonesia Tahun 2009. Jakarta.

Kemenkes RI. (2013). Riset Kesehatan Dasar 2013. Jakarta: Kementrian Kesehatan Republik Indonesia. https://doi.org/10.1007/s13398-014-0173-7.2

Marlingga, I.K.G.A. 2011. Pengaruh Stimulasi Kutaneus: Kompres Panas Basah Terhadap Penurunan Tingkat Nyeri Sensi Pada Lanjut Usia Di Panti Sosial Tresna Werdha Unit Budi Luhur Kasongan Yogyakarta. Skripsi Program Studi SI Keperawatan Universitas Respati Yogyakarta

Ociviyanti, D .2013. Management Acute Pain Cases in Female Daily Life. http://www.google.co.id/url?sa=t\&rct=i\&q=\&esrc=s\&source=web\&cd=1\&cad =rja\&uact=8\&ved=0CCQQFjAA\&url=http\%3A\%2F\%2Fmedicalsevent.net\%2Fdown load-area\%2Fcategory\%2F5-medan-physician-forum

2013.html\%3Fdownload\%3D21\%3Amanagement-acute-pain-cases-in-femaledailylife-prof-dr-dr-herri-s-sastramihardja-spfk-

k\&ei=HrSWUedO8SOuASNsYCYBA\&usg=AFQjCNHnEIN05I42i9SmlkeedCJvzPfzp w\&bvm=bv.68445247,d.c2E

Potter \& Perry. 2009. Fundamental Keperawatan edisi 7. Jakarta: EGC

Ruhyana. (2007). Hipertensi penyebab utama penyakit jantung. http ://ruyana.wordpres.com.

Smeltzer, S \& Bare B.G. (2010). Keperawatan Medikal bedah Brunner \& Sudhart. EGC: Jakarta

Sriminanda, Lyra., Dewi AP \& Indriatii, Ganis.( 2014). Efektivitas Pemberian Jus Tomat Terhadap Tekanan Darah pada Penderita Hipertensi. Skripsi. Program Studi IImu Keperawatan Riau.

Suidah, H., \& Ns, S. K. (2011). Pengaruh Mengkudu Terhadap Penurunan Tekanan Darah pada Penderita Hipertensi di Desa Wedoroklurak Kecamatan Candi Kabupaten Sidoarjo. Jurnal Keperawatan, 1(1).

Vitahealth. 2001. Hipertensi . Jakarta: Gramedia (online)isbn:9792208607

Widyastuti. 2012. Pengaruh Pemberian Kompres Hangat Terhadap Tingkat Nyeri Sendi Pada Lansia Di Panti Sosial Tresna Werdha (PSTW) Propinsi Yogyakarta Unit Abiyoso Pakem. Skripsi Program Studi SI Keperawatan Universitas Respati Yogyakarta. 